\title{
Reports about a highly virulent variant of HIV-1 circulating in the Netherlands is nothing but highly unethical fear-mongering
}

\author{
Dr. Carolina Diamandis ${ }^{1}$, Adrian Tudor ${ }^{1}$, and Olga Ivanova ${ }^{1}$
}

${ }^{1}$ Affiliation not available

February 11, 2022

\begin{abstract}
Chris Wymant and an entire armada of scientists published a small paper titled "A highly virulent variant of HIV-1 circulating in the Netherlands." The general media have picked up on this and are giving the impression that HIV is now a more dangerous infection. This is not the fault of the Wymant and colleagues, but it is highly problematic. This more than 30 years old knowledge, which is now published with big headlines outside the medical press as lurid news, is likely to provoke misunderstandings in the general population. A renewed ostracism and stigmatization of the usual risk groups is now a real prospect. The findings presented in the aforementioned paper should have been addressed exclusively to health professionals and should have better never ended up in the hands of commercial media.
\end{abstract}

\section{Hosted file}

Waymant et al HIV hysteria.pdf available at https://authorea.com/users/410930/articles/ 555504-reports-about-a-highly-virulent-variant-of-hiv-1-circulating-in-the-netherlandsis-nothing-but-highly-unethical-fear-mongering 